\title{
FEMINIDADES CONTRAESENCIALISTAS
}

EN LA DRAMATURGIA ARGENTINA

DE LA POSDICTADURA: UN ESTUDIO

COMPARADO DE LAS REGIONES NOROESTE

y Patagonia

\section{COUNTER-ESSENTIALIST FEMININITY IN POST-DICTATORSHIP ARGENTINE DRAMATURGY -A comparative study in Northwestern and Patagonian regions}

FÉminités CONTRE-ESSENTIALISTES DANS LA DRAMATURgIE POST-DICTATURE EN ARgENTINE : une étude comparative des régions du Nord-Ouest et de la Patagonie

\author{
Mauricio Tossi \\ Doctor en Letras, Magíster y \\ Licenciado en Teatro, Universidad \\ Nacional de Tucumán, Argentina. \\ Investigador adjunto del Consejo \\ Nacional de Investigaciones \\ Científicas y Técnicas (CONICET) y \\ profesor Titular en la Universidad \\ Argentina de la Empresa (UADE), \\ Argentina \\ Eduardo Acevedo 521 1D, CP 1405 , \\ CABA, República Argentina. \\ mauriciotossi@gmail.com \\ https://orcid. \\ org/0000-0001-5144-2544
}

\begin{abstract}
RESUMEN
Durante los períodos dictatoriales, la dramaturgia argentina consolidó una retórica identitaria específica, la cual fue representada estética e imaginariamente a través de la "nación feminizada". Esta figuración femenina esencialista fue objeto de discursos enunciados por los dictadores, así como resignificada por los opositores a los regímenes autoritarios. En consecuencia, este artículo tiene por objetivo analizar la reanimación hermenéutica de esta figuración imaginaria sobre la mujer en las dramaturgias posdictatoriales de la Patagonia y el Noroeste argentinos, con el fin de comprender sus particulares procedimientos poéticos y sus posiciones identitarias contraesencialistas. Para alcanzar este propósito, se utilizan herramientas teórico-metodológicas provenientes de la antropología de lo imaginario (Wunenburger, 2008), la sociología de la cultura (Proaño-Gómez, 2002; Grimson, 2012) y la literatura comparada (Palermo, 2005; Dubatti, 2008).
\end{abstract}

Palabras claves: dramaturgia argentina; estudios regionales comparados; identidad cultural; feminidad; contraesencialismo.

\begin{abstract}
During the dictatorial periods, Argentine dramaturgy consolidated a specific identity rhetoric, which was represented aesthetically and imaginatively through the "feminized nation". This essentialist figuration was the object of speeches pronounced by the dictators, and by the opponents of authoritarian regimes. The purpose of this article is to analyze the hermeneutic revival of this imaginary figuration on women in the postdictatorial dramaturgies of the Argentinean Patagonia and Northwestern Argentina, in order to understand their particular poetic procedures and their counter-essentialist identitarian positions. In line with this, we will use theoretical-methodological tools from the anthropology of the imaginary (Wunenburger, 2008), the sociology of culture (Proaño-Gómez, 2002; Grimson, 2012) and comparative literature (Palermo, 2005; Dubatti, 2008).
\end{abstract}

Received: 2017-08-29/ Accepted: 2017-12-01 / Published: 2019-07-xx DOI: $10.17533 /$ udea.ikala.v24n03a01 
Keywords: Argentine dramaturgy; regional comparative studies; cultural identity; feminity; counter-essentialism.

\section{RÉSUMÉ}

Pendant les périodes dictatoriales, la dramaturgie argentine a consolidé une rhétorique d'identité spécifique, qui a été représentée esthétiquement et imaginairement à travers la «nation féminisée». Cette figuration essentialiste a été l'objet de discours prononcés par les dictateurs et par les opposants aux régimes autoritaires. Le but de cet article est d'analyser la réanimation herméneutique de cette figuration imaginaire sur les femmes dans les dramaturgies postdictatoriales de la Patagonie argentine et du Nord-Ouest, afin de comprendre leurs procédures poétiques particulières et leurs positions identitaires contre-essentialistes. Pour atteindre cet objectif, nous utilisons des outils théoriques et méthodologiques de l'anthropologie de l'imaginaire (Wunenburger, 2008), de la sociologie de la culture (Proaño-Gómez, 2002 ; Grimson, 2012) et de la littérature comparative (Palerme, 2005 ; Dubatti, 2008).

Mots clés : dramaturgie argentine ; études comparatives regionales; identité culturelle ; féminité ; contre-essentialisme. 
Con el regreso a la democracia en 1983, los diversos campos culturales de la República Argentina iniciaron un complejo y dinámico proceso de reconocimiento, abordaje y procesamiento identitario del horror vivenciado durante la última dictadura cívico-militar. Desde una perspectiva histórico-política, este proceso tuvo diversas instancias. Por ejemplo, siguiendo los estudios de Elizabeth Jelin sobre la relación entre Estado y derechos humanos, se puede describir este tiempo en tres etapas: en primer lugar, se plantea una fase de transición (1983-1990), caracterizada por el consenso y la definición de determinadas demandas sociales y jurídicas, como así también por los debates sobre categorías de funcionamiento correlativas a dichas prácticas legales, simbólicas y memorísticas (Jelin, 2005, pp. 509-557).

La segunda etapa (1990-2003) se identifica con la implementación arbitraria de un "olvido jurídico impuesto" por las denominadas leyes de amnistía, esto es, la aplicación de las leyes N. 23492 y N. 23521 (o también llamadas Ley de Punto Final y Ley de Obediencia Debida, respectivamente) y, además, de los indultos decretados por el presidente Carlos Menem. Por lo tanto, esta fase se caracteriza por la lucha pacífica — rigurosa y persistente- de las agrupaciones de derechos humanos contra la impunidad. En este marco, los campos artísticos argentinos - recurriendo a su heterogeneidad poética y regional- formulan numerosas respuestas a los interrogantes emergentes.

El tercer tiempo posdictatorial puede definirse como una fase abierta y, además, en pleno desarrollo por sus continuas y persistentes marcas político-identitarias. Dicha fase inicia en 2003 con la anulación de las leyes de amnistía e impunidad antes mencionadas. A partir de esta específica respuesta legislativa, en las diferentes regiones del país se realizan juicios contra los crímenes de lesa humanidad que, años antes, habían sido silenciados y obturados. En efecto, con la consolidación de dictámenes contra los genocidas se promueven una serie de relaciones políticas e identitarias con alto impacto comunitario, incluso, con proyección en otros campos de derechos humanos y civiles. Vale decir, en esta etapa se faculta un nuevo campo de fuerzas narrativas y discursivas, el cual supera los límites de lo jurídico y se extiende - por su cualidad de plexo simbólico- hacia otras esferas sociales.

Precisamente, en la formación de estos procesos sociocomunitarios, las identidades sexuales y de género, junto con otras tipologías identitarias, se convierten en uno de los campos estratégicos para abordar las diferencias culturales que desafían la posdictadura en su intento de habilitación de un nuevo sujeto democrático. Asumir esta orientación o eje de estudio implica reconocer una específica tradición imaginaria y política que actuó en los años de represión y autoritarismo. De manera puntual, durante los últimos ciclos dictatoriales o de terrorismo de Estado (es decir, entre los años 1966-1983) se establece un particular imaginario sexual y genérico respecto de lo femenino, en el cual la "mujer" es objeto y sujeto de numerosas representaciones sociales esencialistas, totalitarias o maniqueas. Así, en el período posdictatorial se observan respuestas directas o indirectas a aquellas configuraciones identitarias sobre la feminidad, entendidas como tácticas de deconstrucción o intervención estética, tendientes a apoyar los reposicionamientos subjetivos sobre la mujer y su correlativa función cultural en el contexto democrático.

En consecuencia, son múltiples las aristas desplegadas en los estudios y prácticas vinculadas con la identidad del género femenino durante los citados años. Por razones de economía argumentativa, este ensayo se circunscribe a las producciones discursivas contraesencialistas sobre la mujer, desarrolladas por la dramaturgia argentino-regional de la posdictadura. Entonces, de manera específica, esta indagación se acota a los siguientes objetivos o ejes problemáticos: a) interrogar las creaciones teatrales argentinas de la posdictadura a partir de sus posicionamientos identitarios y lógicas de diferenciación sexual, entendiéndolas como posibles réplicas a sedimentaciones patriarcales y autoritarias fortificadas durante los años de horror legitimado; b) comparar las producciones dramatúrgicas argentinas de 
las regiones Patagonia y noroeste argentinos escritas o estrenadas durante la fase 1983-2004, a partir de una invariable o constante común: las figuraciones atribuidas a lo femenino mediante sus nexos con la historiografía y la cultura popular regional; c) analizar las estrategias y los procedimientos poéticos desarrollados por las dramaturgias seleccionadas en su abordaje de la feminidad, con el fin de reconocer qué función estética se le designó a la "mujer" o, mejor, a las "mujeres” en la literatura dramática descentralizada.

\section{Delimitación metodológica y justificación del corpus de análisis}

Siguiendo los estudios de literatura y teatro comparados de Jorge Dubatti (2008) o las investigaciones de Zulma Palermo (1998; 2005) y Luciana Mellado (2010) para las literaturas del Noroeste y la Patagonia, respectivamente, el presente estudio apela a los principios de distinción, conjunción e implicación de la epistemología de Edgar Morin (1994) para desistir del criterio del teatro argentino como "unidad nacional", homologable y reduccionista, es decir, una preconfiguración resultante de categorizaciones estrictamente metropolitanas y conservadoras (Palermo, 1998, p. 63), pues como ha demostrado Néstor García Canclini (1990, pp. 149-190), la homogeneización de las diferencias mediante la fijación de un patrimonio simbólico unificado ha sido una de las tácticas políticas del tradicionalismo sustancialista, por ejemplo, en la elaboración de los proyectos intelectuales y artísticos de los Estados nacionales.

Así, las formas del pensamiento binario develan asimetrías epistemológicas, pues aquello que no se genera en los espacios de poder legitimado es - por contraste- marginal. Entonces, uno de los principales reduccionismos que se deben superar es la reproducción del encuadre centro/periferia en los estudios teatrales contemporáneos en general y en los argentinos en particular. Desde este punto de vista, las investigaciones escénicas regionales no serían una "desviación" del centro, sino un locus de enunciación (Mignolo, 2003; Kadir, 2002) específico y descentralizado, capaz de disolver las dicotomías simplistas mediante su territorialidad geocultural, expresada en las prácticas artísticas objeto de análisis y en las modalidades cognitivas concomitantes. Adoptar esta perspectiva posibilita, en primera instancia, redefinir en términos artísticos el vínculo región/nación, a partir de cartografías que asimilen sus distinciones identitarias pero, al mismo tiempo, afronten sus desigualdades productivas. En consecuencia, la estrategia asumida busca establecer -mediante técnicas comparatistas - redes intelectuales que fracturen la naturalización del tópico centro/periferia y que, a su vez, develen estímulos intrarregionales e interregionales en las teatralidades marginales, esto último, con trazados geoestéticos que compartan una condición política subalterna. En este encuadre metodológico se inscriben, con evidentes implicancias estéticas e ideológicas, las figuraciones de la feminidad que la dramaturgia del norte/ sur ha dispuesto como identidades narrativas.

Para viabilizar este estudio, se ha organizado un corpus de textos teatrales operativos a los objetivos formulados, el cual es el resultado de una exhaustiva investigación exploratoria sobre las historiografías escénicas de las zonas acotadas. Esta muestra puede sintetizarse en los siguientes casos, a partir de los cuales se desarrollará una "triangulación comparada”, a saber:

a) Textos dramáticos del Noroeste Argentino (1983-2004): Clemencia, de Raúl Dargoltz; Cruzar la frontera, de Jorge Accame; Siempre lloverá en algún lugar, de Manuel Maccarini.

b) Textos dramáticos de la Patagonia argentina (1983-2004): Pasto verde (reflexión dramática en un acto), de Lilí Muñoz; Camino de cornisa, de Alejandro Finzi; Bálsamo, de Maite Aranzábal; Hebras, de Luisa Calcumil y Valeria Fidel. 


\section{Dramaturgia, dictadura y feminidad: el esencialismo nacionalista a través de sus metáforas corporales}

A partir de la dictadura autodenominada "Revolución argentina” (1966-1973) y sus consecutivos períodos totalitarios y autócratas (1975-1983), la historiografía política nacional ha consolidado, mediante diversos lenguajes y agentes públicos, una determinada retórica corporal: la nación feminizada. Desde esta perspectiva de estudio, las investigaciones de Lola Proaño-Gómez (2002) develan - con exhaustividad- los mecanismos estéticos e ideológicos de aquella figuración nacionalista. Esta representación social, desarrollada por citada autora, puede resumirse en las siguientes ideas:

La metáfora del cuerpo aparece, por primera vez en este período, en el discurso paternalista y autoritario de [Juan Carlos] Onganía. Desde su discurso, el cuerpo como metáfora de la nación se elabora de diversas maneras: la nación aparece como cuerpo político del cual la "Revolución Argentina” y Onganía como su representante, es la cabeza, el lugar de la inteligencia, del espíritu y del alma. Desde esta propuesta, el cuerpo, asimilado a la materia y opuesto al espíritu no puede prescindir de su protección ni de la guía de la inteligencia y de la razón. El discurso de Onganía propone además, la metáfora de Padre protector como el creador y fecundador de la nación, lo que da lugar a la imagen de la nación feminizada o representada como una joven necesitada de guía y protección. Por último, el discurso de Onganía propone la imagen del Padre como el médico/salvador del cuerpo político, es decir de la nación representada como un cuerpo enfermo, espiritual y físicamente (2002, pp. 98-99).

Así, Proaño-Gómez expone las estrategias de control y sujeción de la nación a través de su feminización, ya que esta metáfora reproduce ciertos tópicos autoritarios relacionados con los dogmas cristianos, asociados con la pasividad, la sensibilidad y el pathos (p. 138). Por lo tanto, el discurso patriarcal de los dictadores presenta esta nación feminizada como una joven virgen, pasiva y receptora, a la que los "padres" y "guardianes" del orden, la espiritualidad y los valores del Estado deben cuidar, proteger y educar.
A partir de esta retórica corporal opresora, la cual se expande y diversifica a través de sus variados arquetipos paternalistas, Proaño-Gómez analiza los discursos de la resistencia cultural, pues en las respuestas de la oposición también se desarrolla una figuración feminizada de la nación, aunque en este caso el cuerpo/mujer no es fertilizado por el pater familias; por el contrario, estas fracciones progresistas lo conciben "[...] como un cuerpo violado y devorado por los agentes de la normalización económica, y localizan la enfermedad y la desintegración en el Padre y en los representantes de los grupos que eventualmente lo apoyan" (p. 100).

Esta estructura imaginaria —instituida en los años de represión y terrorismo estatal, pero con vigencia en praxis actuales asociadas a sus intelectuales orgánicos - es considerada un patrimonio o legado inherente a la "argentinidad" y, por ser tal, devela una de las modalidades del esencialismo nacionalista. Este tradicionalismo sustancialista ejerce sobre la feminización un complejo proceso identitario, el que ofrece a las prácticas simbólicas nacionales un notorio desafío: deconstruir este modo de ser dominante, prefijado y apriorístico en "configuraciones" culturales y subjetivas dinámicas. Según la propuesta teórica de Alejandro Grimson (2012), las retóricas esencialistas se disuelven a través del examen de las experiencias históricas desigualmente compartidas (p. 45), es decir, comprender esta "configuración" de lo femenino como discurso identitario implica indagar en la complementariedad, la integración y la historicidad de las partes o fragmentos de las figuraciones sedimentadas, para reconocer la constitución de su hegemonía.

Por su proyección histórica, la configuración "nación feminizada" secompone, a su vez, de múltiples figuraciones que forjaron estructuras cognitivas comunes, quizá cercanas a las denominadas thematas, esto es, unidades epistémicas resistentes y estables que modelan acciones y percepciones sociales de distinta naturaleza (Banchs, 2007, p. 74). Estas figuraciones sedimentadas durante los años de represión y horror sistematizados pueden comprenderse de forma 
dinámica a través del siguiente modo: en los estudios de Proaño-Gómez (2002), lo femenino está asociado, por un lado, a distintos binarismos machistas (activo/pasivo, inteligente/sensible, padre/madre), donde se reserva el primer tópico de la dualidad al lugar de representación del dictador (activo, inteligente y padre), tal como ha demostrado la autora mediante el análisis de los discursos públicos seleccionados en su investigación; por otro lado, se encuentran figuraciones femeninas que, según el discurso oficialista o las prácticas contraculturales, obtienen disímiles estructuras semánticas, esto es: a) la nación feminizada como una territorialidad asaltada y violada; b) el cuerpo/nación/mujer recluido, enfermo y, principalmente, fustigado por la locura; c) la fecundidad de lo erótico como soporte para la emergencia de un cuerpo utópico.

La gramática identitaria del cuerpo/mujer deconstruida por Lola Proaño-Gómez a partir de sus estudios sobre el teatro, la lírica popular y los discursos públicos de dictadores u opositores del régimen de facto de 1966-1973 no ha sido - hasta nuestros días - estudiada como una lógica imaginaria, es decir, como una configuración activa, con historicidad y pregnancia simbólica en las fases posdictatoriales, pues, como señalan los estudiosos del tema (cfr. Ricoeur, 2000; Castoriadis, 2013), una determinada lógica imaginaria no caduca o se clausura por un fenómeno singular (ya sea individual o colectivo); por el contrario, una lógica imaginaria se caracteriza por su capacidad para sistematizar imágenes a partir de los principios de autopoiesis, autorregulación, transformación innovadora y recreación (Wunenburger, 2008, p. 17).

Por consiguiente, la tensión entre lo sedimentado y lo dinámico de estas figuraciones sobre lo femenino permiten diagramar un problema específico y sin estudios previos en los campos teatrales regionales, a saber: en el retorno a la democracia, ¿cómo abordaron los dramaturgos regionales entendidos como agentes directa o indirectamente afiliados con las fracciones intelectuales de resistencia que actuaron durante la dictadura - la retórica corporal del sustancialismo paternalista que, como ya se indicó, entendía la feminización como una figuración de lo nacional, operativa y hegemónica?

Para analizar esta configuración cultural en la dramaturgia argentino-regional se tomarán como base algunas herramientas metodológicas de la antropología del imaginario, principalmente los lineamientos conceptuales desarrollados por Jean-Jacques Wunenburger. Este encuadre teórico permite reconocer la evolución y dinámica de una determinada lógica imaginaria, a través de factores intratextuales, infratextuales $\mathrm{y}$ supratextuales $(2008$, p. 35$)$, esto último, independientemente del soporte (lingüístico o visual) de las representaciones. Por lo tanto, el corpus de obras teatrales seleccionado asumirá como eje de análisis la dimensión supratextual sobre la feminidad desarrollada por las dramaturgias norteñas y sureñas en la posdictadura.

Asimismo, indagar en la figuración imaginaria y esencialista de la "nación feminizada" requiere una toma de posición frente a las distintas teorías sobre la identidad femenina o de género. Por los encuadres y objetivos descritos, este estudio tomará como marco de referencia las investigaciones de Elsa Drucaroff, quien -mediante una rigurosa articulación epistémica- aborda la feminidad como una racionalidad alternativa, elaborada a partir de un constructo semiótico que funda "otros" regímenes simbólicos, de clase y de género, ante las formas de dominación falo-logocéntricas. En efecto, la citada autora recupera las formas identitarias que se sostienen en el "feminismo de la diferencia”, es decir, una semiosis diferencial y alternativa que puede entenderse como "otro logos", sin caer en los esencialismos del cuerpo/mujer. Al respecto dice:

Porque un cosa es advertir contra el pensamiento mecánico y esencialista en el que el cuerpo, como organismo supuestamente ajeno a la cultura, produciría necesaria, automáticamente y siempre ciertas significaciones, y otra muy distinta es rechazar de plano que nuestra diferencia sexual, a la cual el patriarcado transforma en cero, en agujero, en nada, pueda hablar y significar otra cosa (Drucaroff, 2016, p. 257). 


\section{Figuraciones antiesencialistas}

de la feminidad en la dramaturgia Norte/ Sur (1983-2004): estudio de casos

En correlación directa con lo anterior, en este artículo se analizarán dos planos o proyecciones teatrales de la lógica imaginaria ya descrita, con énfasis en los siguientes ejes de comparación: 1) la reanimación hermenéutica del encierro y la locura del cuerpo/mujer; 2) la impugnación de.l discurso tradicionalista y autoritario, mediante una resemantización de la mujer/territorio. Por ende, estos ejes se definirán como secuencias activas o componentes dinámicos de un "imaginario social instituido", esto es, la continuidad, reproducción o repetición de formas imaginarias idénticas que regulan determinadas relaciones intersubjetivas y comunitarias (Castoriadis, 2013).

\section{La recreación hermenéutica del encierro y la locura}

Esta estructura imaginaria "instituida” o sedimentada tiene, a su vez, la capacidad de reactivar sentidos en nuevos contextos, una actividad que se puede comprender como reanimación hermenéutica de dichas figuraciones (Wunenburger, 2008, p. 90). Así, las representaciones del encierro y la locura como encuadres ficcionales para el tratamiento teatral de personajes femeninos durante las fases dictatoriales se tornan, mutatis mutandis, en tópicos resemantizados durante la etapa posdictatorial.

Esta red imaginaria puede observarse con claridad en las siguientes producciones dramatúrgicas regionales: Clemencia (1987) de Raúl Dargoltz, ${ }^{1}$ Hebras (2004), de Luisa Calcumil y Valeria Fidel; ${ }^{2}$ Siempre lloverá en algún lugar (2001), de Manuel Maccarini, ${ }^{3}$ y Bálsamo (2004), de Maite Aranzábal. ${ }^{4}$

\footnotetext{
1 Dargoltz, 2007.

2 En Tossi, 2015.

3 Maccarini, 2014.

4 En Tossi, 2015.
}

En efecto, si en los períodos dictatoriales las configuraciones escénicas sobre la feminidad se cristalizaban en imágenes de encierro asociadas con los manicomios $\mathrm{u}$ otros espacios de opresión, o también se relacionaban con una corporeidad nacional "enferma", en el regreso a la democracia esta themata permanece en múltiples textos dramáticos, pero adopta modificaciones sintácticas y semánticas acordes a los nuevos marcos históricos de enunciación.

Desde este punto de vista, Clemencia, una obra inaugural del teatro norteño en la posdictadura, fue el resultado de un trabajo de campo sociológico y artístico coordinado por el autor e investigador Raúl Dargoltz, quien - junto con su grupo de teatro- realizó durante el año 1986 visitas sistemáticas al Hospital Neuropsiquiátrico de Campo Contreras, situado en la provincia de Santiago del Estero. Mediante procedimientos que tienen aires de familia con el docudrama o teatro documental de los años sesenta y setenta, esta obra recrea la vida de seis internos del mencionado centro de salud mental: un ciego perteneciente a una tradición familiar de políticos locales; una mujer abandonada por sus hijos; un estudiante universitario que padece surmenage; un maestro que - luego de ejercer por años su profesión en escuelas rurales - adquiere rasgos psicóticos; un amante que enloqueció al matar a su esposa por celos y, finalmente, Clemencia, una madre que - por la imperiosa falta de recursosdecidió regalar a sus hijos, acción que la hunde en un profundo desasosiego. Precisamente, en este último personaje - sinécdoque de las numerosas madres latinoamericanas en idéntica situación de desamparo- gravita el título de la obra, con evidentes connotaciones sociales y éticas que subyacen en su nombre: "clemencia".

A diferencia de los textos teatrales del período anterior, caracterizados por situar a sus personajes femeninos en contextos de reclusión o violencia y, desde allí, construir una metáfora del ejercicio autoritario y represivo sobre el cuerpo/nación/mujer, en este caso, la pieza muestra la rebelión de los locos hacinados, cuyo motor central es ayudar a Clemencia a 
recuperar a sus hijos. Por lo tanto, estos cuerpos abyectos, residuales y marginales logran escapar del manicomio e inician un periplo antiheroico: recorrer los principales símbolos urbanos de ciudad de Santiago del Estero, exponiéndolos como documentos históricos del poder patriarcal y oligárquico de aquella región. Entonces, estos personajes "deshechos" caminan por la famosa Avenida Belgrano, la Universidad, el Banco Provincia, el Teatro 25 de Mayo, hasta llegar a la Legislatura, un ícono espacial de las luchas sociales y de la reapertura democrática. En este peregrinaje Clemencia y sus compañeros desnudan — con fundamentos historiográficos que admiten la contrastación empírica de los datos- las paradojas culturales de esa zona, al enunciar causalidades que también responden a sus respectivas condiciones subalternas. Incluso, a través de esta configuración de la "loca" que entrega a sus hijos, el autor construye una alegorización con las Madres de Plaza de Mayo, pues, dice la protagonista: "Ella no quiere taparse el rostro. Ella se va a poner un pañuelo blanco, porque soy madre, en nombre de las madres que perdieron a sus hijos. Yo perdí como treinta mil hijos. (Dargoltz, 2007, p. 139)". En suma, en este texto teatral, el esencialismo nacionalista es refutado - en términos brechtianos - por la "muestra" de gestus sociales que develan la naturalización de múltiples contradicciones históricas y políticas, propias del discurso patriarcal santiagueño.

En el vértice sur del mapa teatral trazado, la obra Hebras, de Calcumil y Fidel, expone las formas de violencia y opresión que viven Laila e Inacal, dos mujeres en un cautiverio psiquiátrico. Ambas intentan subsistir a las violaciones y otros vejámenes, mientras recuperan — por el solidario ejercicio de recomponer fragmentos olvidados- algunas "hebras" de su extraviada memoria. Así, mediante recursos simbólicos y expresionistas, se observa en escena canciones, ritualidades, fantasías, anhelos y ominosas reminiscencias sobre un pasado abrumador, un tiempo subjetivo que, a su vez, opera como fundamento central de aquel pathos. Ante la pregunta acerca de cuál es la causa del sufrimiento y encierro de estas mujeres, solo encontramos las arbitrariedades y los sinsentidos totalitarios, siendo los básicos e inocuos principios de libertad y erotismo ejercidos por las protagonistas los que funcionan como pecados de hybris en la organización del relato.

En este caso, es factible reconocer un puente semántico entre esta configuración femenina patagónica y las citadas metáforas del cuerpo/nación/ mujer de las fases dictatoriales, pues ambas comparten una misma composición imaginaria $\mathrm{y}$ cognitiva: la mujer enferma, en cautiverio y ultrajada por un sistema de poder déspota, tal como exponían las obras canónicas del período anterior; por ejemplo, El campo (1968) de Griselda Gambaro. No obstante, estos parecidos de familia deben ser resignificados en las lógicas culturales de la posdictadura, en cuanto no aluden a una tesis social sobre la argentinidad, sino a un "trabajo de la memoria" (Jelin, 2002), focalizado en su capacidad para abordar el "presente del pasado" y resemantizar las contradicciones históricas sobre determinadas subjetividades vulneradas y sometidas. De este modo, Calcumil y Fidel proponen una isotopía dramatúrgica que objetiva esta visión, al decir: "Estos hilos son mis venas; esta hebra, mi memoria, siempre ato los hilos cerca del cielo" (2015, p. 206).

La mujer violentada, enferma y aislada como una figuración imaginaria que cruza transversalmente a la dramaturgia argentina desde los años 1960, llega a los complejos albores del siglo XXI a través de otra reanimación hermenéutica, esto es, el encierro femenino con bases en un expresionismo social, aunque el espacio tortuoso de la reclusión no es, necesariamente, un manicomio.

Esta autorregulación poética puede leerse en la obra Bálsamo, de Maite Aranzábal, en la que se propone la siniestra convivencia de tres personajes: Verónica García, una museóloga que llega a la ciudad de General Roca (provincia de Río Negro) para ejercer su profesión en una institución local, el General de La Serna y el cacique tehuelche Cushamen, ambos sujetos/objetos embalsamados y exhibidos en el museo. Con ellos, la protagonista rememora sus infortunios amorosos y reabre sus heridas al 
reproducir los mecanismos de un erotismo avasallado que no encuentra un "bálsamo" eficaz, como así también se interroga sobre el valor simbólico de los cuerpos y la densidad social de la memoria.

En esta dúctil y estimulante estructura ficcional hallamos una construcción espacial singular, que opera como metáfora cultural del dolor sobre las muertes abyectas y proscritas, nos referimos al "museo" como ámbito de conflictividades en el establecimiento de un pasado histórico y de una identidad social.

Por consiguiente, en esta obra, el museo es un espacio subjetivado y devela una doble lectura: primero, es un lugar de conmemoración y de afianzamiento de una "tradición selectiva" (Williams, 1994), pues la autora convierte en "museables" a determinados componentes de la historiografía patagónica, al resignificar — desde un ámbito geocultural periférico- las luchas de los pueblos originarios como fragmentos de los olvidos jurídicos y sociales vigentes; segundo, el museo es un ámbito estratégico para develar y teatralizar una lógica siniestra, la de la compulsión a la repetición de una forma masculina de poder y erotismo que - de manera persistentesubsume a la protagonista en un ciclo sin fin, agobiante y lacerante, pues cuerpos vivos y muertes, activos o mutilados, ratifican de igual modo la premisa que define a nuestra nación como "un país de hombres".

Ambas lecturas muestran un "duelo" inconcluso que -en términos freudianos- ubica a esta mujer a un estado de inerte "melancolía" y, desde esta plataforma argumental, se expone la mencionada metáfora sobre la memoria individual y colectiva de las innumerables y silenciadas "muertes sin escena” (Schnaith, 2005) que la historia regional ha promovido, al confinarlas al olvido y restarles la posibilidad de una legítima representación. Vale decir, la estructura ficcional de Bálsamo ofrece a aquellas muertes sin escena una lógica imaginaria contraesencialista, con el fin de revestir lo inefable u ominoso con múltiples contradicciones históricas.
En el norte, polo opuesto a la cartografía del texto anterior, la obra Siempre lloverá en algún lugar, de Manuel Maccarini, permite reconocer otro modo de reactivación sintáctica y semántica en la figuración mujer/locura/encierro heredada de los años dictatoriales. En este caso, los tópicos del aislamiento y la enfermedad dialogan con hipertextos contemporáneos, aunque la indicada estructura imaginaria se conserva. Por ejemplo, el autor tucumano incorpora en las bases del relato su propia concepción estética del travestismo escénico y del mito de la animalidad.

Así, en la mencionada pieza, dos hermanas -Clotilde y Emma, representadas por dos intérpretes varones - viven un encierro voluntario en su propia casa, pues el afuera les resulta amenazador e invasivo. Ellas están a la espera de una lluvia renovadora. Sus cuerpos han mutado hacia rasgos varoniles (bigote, voz, etc.) y continúan en ese proceso degenerativo sin saber qué devendrán. El miedo no solo les impide vincularse con los otros, sino también les exige sofisticadas técnicas de persuasión, por ejemplo: salir a la calle con vestimentas de mendigo para no ser reconocidas ni dar cuenta de su alta posición económica, o comprar armas de fuego de última tecnología, entre otras. La acción avanza con la supuesta visita de Salvio, un compañero de Clotilde en la universidad de los años setenta, quien — según la percepción del mundo que ellas mantienen - se ha transformado en un perro y, luego, lo hará en una cucaracha. Finalmente, ambas mujeres, con sus cuerpos cada vez más violentados por el surgimiento de extrañas protuberancias, no pueden reconocer al verdadero Salvio cuando este se anuncia bajo los signos de la esperada tormenta, que resignifica su carácter redentor.

Siempre lloverá en algún lugar le propone a sus personajes femeninos otra forma de abyección, vinculada con las intersubjetividades de la política contemporánea y, quizá, cercana a la noción de "cuerpo utópico" (Foucault, 2010) por lo contingente de su identidad y por ser el "punto cero del mundo” (p. 16). No obstante, esta feminidad 
dislocada es nuevamente figurada a través del encierro. Entonces, en la citada obra se observa un espacio dramático que condice con la somatización utópica de lo femenino: el living de una casona en el que sobresalen los colores rojo y rosa viejo, telas de arañas, polvo y otros signos de profunda decadencia o, como dice el autor, "semejan tumbas en el olvido" (Maccarini, 2014, p. 79). Allí, bajo un recurso metonímico, conviven lo manifiesto - un desproporcionado y desmesurado sillón, plataforma de toda la acción a lo largo de la obra- y lo latente, un sótano, cuya entrada está debajo del mismo sillón y al que acceden los personajes toda vez que se remitan al interior de la vivienda. Este boceto espacial y somático, en el que la reclusión, el fracaso y el miedo forman parte de su arquitectura, permite en términos retóricos establecer tensiones con un espacio político e identitario alternativo, hierático y libre, en el que la utopía se manifiesta en la lluvia, en el afuera renovador, por esto: "siempre lloverá en algún lugar".

\section{8 \\ La resemantización del cuerpo/mujer/ territorio}

David Le Breton (2002) ha demostrado que el cuerpo es un significante social estratégico para el estudio de lo imaginario, pues, dada su investidura colectiva opera como soporte de prácticas, discursos y sentidos específicos. Así, el cuerpo es - por su espesura semántica - una ficción, y funciona como frontera viva en determinadas territorialidades simbólicas, es decir, el cuerpo es una estructura imaginaria que construye "soberanía", al establecer diferenciaciones del mundo, de los otros y de sí mismo.

Siguiendo esta concepción epistemológica del cuerpo es dable señalar que la "nación feminizada" recupera, desarrolla y transforma las figuraciones femeninas de las fases anteriores según las específicas condiciones sociopolíticas de la posdictadura en las regiones norte y sur del país, ya que se afianza la metáfora de la mujer/nación/ territorio, aunque en esta reactivación hermenéutica se potencia la noción de "mujer/frontera", al tomar como referencia a las luchas geoculturales e independentistas del siglo XIX; pues a través de esta estrategia poética se impugnan los esencialismos tradicionalistas y autoritarios heredados de los enunciados dictatoriales.

Un caso de estudio operativo en el abordaje del tópico "mujer/frontera" es Camino de cornisa, de Alejandro Finzi (1986), cuya organización textual puede dividirse en cinco macrosecuencias escénicas. Primero, la acción comienza con la vigilia de un joven soldado argentino del ejército dirigido por el general Julio Argentino Roca, durante la denominada Conquista del Desierto (18791885). Es una secuencia breve, sin diálogos, pero relevante en la estructura ficcional por su función, esto es, dar inicio al mecanismo narrativo de la prolepsis, desarrollada mediante un signo sonoro que anticipará a lo largo de la obra la aparición de un ser inhumano, alado y feroz. Segundo, se muestra la travesía de dos matrimonios burgueses y su chofer, quienes viajan en automóvil por la Patagonia desde Buenos Aires en el año 1942, con el fin de llegar a la ciudad de San Carlos de Bariloche para la reapertura de uno de los hoteles de mayor prestigio en Sudamérica: el Llao Llao, un emblema de la oligarquía regional. En esta secuencia, la acción — sin un conflicto determinante- está centrada en el creciente malestar físico de Isabel, frente a la ilusión de los hombres (Enrique y Eduardo) por llegar a su destino, con la pretensión de concretar sus negocios con los extranjeros que visitan el país en el contexto especulativo de la Segunda Guerra Mundial. Tercero, se narra la imposibilidad de continuar el viaje por la ruptura del motor del automóvil. A su vez, la enfermedad de Isabel avanza sin explicación racional y se intensifica la presencia, latente y ominosa, del monstruo que dio inicio a la escena, esto último, mediante un efecto sonoro que es percibido únicamente por la mujer convaleciente. Cuarto, con los viajantes varados en medio de la "nada", sin poder continuar su romería, aparece Sebastián, un viejo soldado de la Conquista del Desierto, quien exiliado en el tiempo y portando un oxidado fusil Rémington - exige, bajo amenaza, que se cumpla la promesa del general Roca de entregar 
tierras patagónicas a los enrolados en aquella campaña militar. Progresivamente, las incoherentes alusiones de Isabel sobre un ser peligroso y sanguinario que los asecha serán escuchadas por el chofer y Sebastián, con lo cual se conforman nuevas relaciones de oposición entre los personajes. El conflicto de esta secuencia se resuelve con el asesinato de Sebastián por parte de Enrique y Eduardo. Quinto, la escena presenta a sus protagonistas en la lejanía del camino y expone el punto final de la prolepsis, esto es, la metamorfosis de Isabel en el mítico Pihuchén — serpiente alada de la cultura mapuche-, quien devora los restos del cadáver de Sebastián $\mathrm{y}$, de este modo, lo revive y transforma en otro Pihuchén.

En este texto, la representación imaginaria mujer/ territorialidad se manifiesta en la metamorfosis del cuerpo de Isabel al cruzar una frontera o espacio liminal. Por su apropiación de recursos poético-simbolistas, la obra promueve situaciones de pasaje o conexión, de viaje o transformación desde el régimen empírico hacia la alteridad. Así, el relato se funda en el peregrinaje de estos antihéroes por los misteriosos confines de la Línea Sur rionegrina y en su correlativa metamorfosis, ya sea corporal o espiritual. En el plano de la intriga, sabemos que Isabel comienza a sentirse "enferma" (inicio de su mutación o transformación física) al cruzar el Río Colorado, punto geográfico que marca la división interna de la Patagonia con otras regiones del país y, por ende, ícono de una cartografía política que ha sido motivo de numerosos conflictos territoriales en las comunidades de los pueblos originarios de la zona, en especial, a partir del regreso a la democracia. De este modo, el viaje es para el cuerpo de Isabel un "rito de pasaje", una ceremonia en la que vivirá en carne propia la ominosa leyenda del Pihuchén, contada por su padre desde niña.

En Camino de cornisa, las fracciones sociales oligárquicas, responsables de las matanzas de los pueblos mapuche y tehuelche con la despectiva "conquista del desierto" y, décadas posteriores, siendo dirigentes activos del pensamiento ultraconservador que dirigió y avaló los distintos procesos dictatoriales del país, se confrontan aquí con una lógica imaginaria que reivindica lo fronterizo, para que en esa feminidad nazca lo mágico. Entonces, el cuerpo/mujer/territorio rompe con sus esencialismos adjudicados por la tradición dictatorial y propone una reactualización sintáctica y semántica en dicha representación imaginaria: ¿cómo habitar en una tierra históricamente violentada, caracterizada además como un margen fronterizo, lábil y sin tiempo? Estos soportes imaginarios y territoriales se objetivan en el cuerpo de Isabel, con el fin de convertir esa corporeidad en un espacio liminal y de intercambio, fértil y alquímico, en donde lo maravilloso y lo conflictivo de la historia regional obtiene una singular prolificidad.

Paralelamente a esta búsqueda estética, la retórica corporal de la mujer/frontera obtiene en los discursos teatrales posdictatoriales del norte y el sur argentinos otra actualización hermenéutica, esto es, el personaje de la cuartelera, también llamada soldadera o fortinera. Esta figuración femenina alude a la mujer que vivía en los cuarteles militares durante las distintas campañas decimonónicas de los ejércitos nacionales y, por sus trabajos sexuales y domésticos, era incorporada a las milicias, aunque sin los derechos otorgados a los varones.

Esta particular representación imaginaria e historiográfica sobre la mujer se encuentra claramente configurada en las obras Pasto verde (reflexión dramática en un acto), de Lilí Muñoz - estrenada en 1997-, y Cruzar la frontera, de Jorge Accame.

En relación con el primer caso, la dramaturga neuquina aborda un personaje típico de la cultura popular patagónica, la conocida Pasto Verde. La tradición oral presenta a esta mujer como una de las cuarteleras del ejército de Julio Argentino Roca durante la Conquista del Desierto, quien prestó "servicios" a dichas tropas durante sus arremetidas contra los pueblos originarios en los fuertes de Puan o Trenque Lauquen, hasta establecerse como comerciante en una aguada de Plaza Huincul. Hoy, en esta última localidad, se erige un altar a "La 
Pasto Verde”, por ser una de las fundadoras de esa ciudad y, además, por sincretizar en su apodo militar la fertilidad anhelada en aquellos páramos sureños. Este personaje histórico es recreado en la citada pieza teatral mediante aporías identitarias, pues en la feminidad de Pasto Verde se condensan o sintetizan determinados comportamientos paradójicos (erotismo/expiación, sensibilidad/insensibilidad, activismo/letargo, sumisión/sedición), los que disuelven los esencialismos sedimentados.

El texto de Muñoz está organizado en cuatro macrosecuencias dramáticas, las cuales contienen recursos elípticos que generan un relato fragmentado y acrónico. En este desarrollo ficcional se exponen los conflictos identitarios de Pasto Verde con su marido, Campos, un oficial que - en el trascurso de la acción- decide abandonarla para desertar del ejército. Los actantes o fundamentos de valor de las primeras escenas radican en la desazón e incertidumbre sobre el rol que ambos ocupan en la consolidación de la "patria" por medio de la matanza de los pueblos indígenas. Por ejemplo, el esposo dice:

No sé qué hacer, Carmincha. Ya no sé qué defiendo. Ni siquiera sé si te defiendo... Mi patria... Si vos sabés que la patria que tengo, la única, es este pedacito de tierra en el desierto y vos, el rancho, los animales, el buscar - de puro soñador nomás - esos lloraderos de alquitrán que no te gustan [...] (Muñoz, 2007, p. 185).

Frente a estos dilemas "masculinos", los que sin embargo - connotan cierta "pasividad" en el sometimiento ideológico de los soldados ante el objetivo económico y político de la usurpación de tierras patagónicas, Pasto Verde reacciona de modo “activo", enérgico y tenaz, para sobrevivir al yugo sexual en los cuarteles y resistir - entre balidos y vientos sureños - ser una mujer sin hombre y, por lo tanto, una mujer sin tierra.

La decisión de la protagonista de no acompañar a su marido en la deserción la masculiniza. Este habitus paradojal es lo que genera, en términos objetivos, su posición contraesencialista; pues, si bien Carmen Funes está enajenada por los mecanismos patriarcales y autoritarios de los fortines y, por ende, convertida en "carne" disponible para el goce de los militares superiores, ella no es una mujer "seca", débil o enferma que requiere de la imperiosa ayuda de un padre protector; por el contrario, en esta configuración imaginaria ella es " $\mathrm{La}$ Pasto Verde", un apodo que los propios castrenses le asignan y que opera como metáfora de la fecundidad que escasea en esos terruños áridos. Así, Pasto Verde es una mujer/territorio, cuya composición supratextual o polisémica condensa múltiples posicionamientos contraculturales y contraesencialistas: primero, se opone al ideologema de la "desertización" que fundamentó las ya mencionadas campañas militares, dado que en la llamada "Conquista del Desierto" no había desierto alguno, sino una sólida y potente organización comunitaria, con la población de mapuches, tehuelches, pehuenches, onas y otras fracciones sociales que eran "obstáculos" en el afincamiento de las fuerzas productivas de la oligarquía terrateniente metropolitana. Esta visión sobre el desierto operó - y continúa haciéndolo- como una "frontera", con impacto en planos geopolíticos, económicos, e identitarios. Segundo, se resignifican dos tópicos descendientes de la lógica imaginaria objeto de estudio; por un lado, se aborda la idea de progreso, ya que en la infertilidad superficial o aparente de esos suelos, ella predijo — según cuenta la tradición oral que envuelve a La Pasto Verde- el descubrimiento del petróleo, "agua que da fuego" (p. 188) o "lloradero de alquitrán" (p. 185) y, de ese modo, se estableció la principal actividad económica de la zona. Por otro lado, se resemantiza la metáfora de la mujer/nación como territorio violentado que requiere ser liberado o sanado de un virus o enemigo interno que la contamina. Sobre esta figuración esencialista y maniquea, la obra de Muñoz autorregula la imagen del hostigamiento sexual, mediante la personificación histórica de la cuartelera y su correlativa denigración, en cuanto es carne que brinda placeres y servicios. Así, el cuerpo femenino es una analogía de las tierras por gobernar; es un cuerpo "necesario", porque en ella se sostiene y proyecta el sistema político-militar de conquista, gracias al cual el régimen funciona - pues sin goce sexual de los soldados no habría 
control de las tropas-; además, es un cuerpo al que se le aplican las mismas tácticas ominosas que a los terruños por colonizar: violación, ocupación y explotación. Este cariz imaginario e identitario de la representación mujer/nación/territorio obtiene, en la obra teatral Pasto verde, un perfil romántico, también otorgado a su configuración religioso-popular.

Finalmente Carmen Funes logra ser una mujer sin hombre pero con tierra, en suelo fértil y rico; no obstante, y aquí se observa otro aspecto de la aporía inscrita, su muerte - según la propia mitología regional- es consecuencia de dicha fecundidad, puesto que muere en situación de parto.

Al retomar esta composición paradójica en la personificación de la heroína, Muñoz incorpora a su pieza una última macrosecuencia dramática, un colofón que rompe con la organización poética de los tres cuadros anteriores, los que tenían parecidos de familia con un realismo extrañado o épico por su tendencia alegórica e histórico-figurativa. Este quiebre poético se observa en la cuarta secuenciación escénica, cargada de lirismo, opacidad y proyecciones subjetivas que acercan el texto a procedimientos expresionistas. Puntualmente, en dicho cuadro dramático se presenta a Carmen Funes en una letanía acuciante, rodeada por los reflejos simbólicos de la cüyen (o küyen, es decir, "luna” en mapudungun) e invadida por el sagaz viento patagónico, además, la protagonista es inquirida por un ángel-títere, esto es, una extensión ominosa de su bebé muerto al nacer. Este epílogo teatral, el que no condice con las lecturas de la religiosidad popular ni con las que este personaje obtuvo en el cancionero nacional, conlleva una nueva apropiación del themata mujer/ nación/territorio desarrollado en la dramaturgia de los años dictatoriales, el cual se sintetiza metafóricamente en la mirada final del personaje central, quien dice: "Y el desierto navega / con nosotros adentro" (Muñoz, 2007, p. 189). De este modo, el "desierto" en sus múltiples acepciones o contradicciones históricas (ya sea como ideologema operativo a una concepción tradicionalista y reaccionaria del país o como símbolo de prácticas contraculturales y de resistencia política) se reanima hermenéuticamente en un "adentro", en una nueva imagen de la "frontera”, cartografiada como un interior femenino, dinámico y perseverante.

Desde la visión comparatista elegida para este estudio, la región Noroeste presenta numerosos casos de textos teatrales que condicen con esta lectura identitaria, al reelaborar la retórica de la "nación feminizada” a partir de tópicos telúricos, por ejemplo: la mujer/tierra, férrea y sapiente, asociada con la Pachamama o con sus consecuentes posicionamientos matriarcales, es resignificada en el marco de la posdictadura a través del semema ya indicado, esto es, la "mujer/frontera", entendida como una hipertextualidad barroca (Wunenburger, 2008, p. 43) que fusiona elementos provenientes de la simbología de los pueblos andinos prehispánicos, de la cultura grecolatina clásica y de los componentes imaginarios consolidados durante las fases dictatoriales en los discursos públicos. Algunos casos paradigmáticos de esta variable de análisis sobre el norte argentino son: Los ojos de la noche, de Verónica Pérez Luna; Jueves de comadres y Casa de piedra, de Jorge Accame; Eidos, de Nicolás Aráoz; Jamuychis... el grito, de Patricia García y Flavia Molina; Rosas de sal, de Jorge Paolantonio; El sueño inmóvil y Por las hendijas del tiempo, de Carlos M. Alsina; Encallados buques callados, de Mario Costello; El ombligo del sol, de Manuel Maccarini; entre otros.

Por razones de economía argumentativa y, ante la productividad estética de esta variante norteña, se abordará como caso testigo la obra Cruzar la frontera, de Jorge Accame, pues en ella se condensan y ejemplifican los registros supratextuales utilizados en otras dramaturgias de la región.

En esta pieza se retoma la figura femenina de la cuartelera o soldadera, aunque en esta textualidad el rol de la fortinera está vinculado con los procesos históricos del norte argentino, en un corte sincrónico similar al planteado en la visión sureña de Pasto Verde, es decir, el siglo XIX y sus luchas independentistas e identitarias. Así, nuevamente el 
período de formación del Estado nacional es una estructura significante estratégica en la organización poética de los relatos escénicos en ambos polos del país, mediante los cuales se reproducen o transforman determinadas representaciones-imaginación sobre la mujer/nación/tierra.

De manera puntual, el citado texto teatral de Accame está escrito en tres cuadros dramáticos breves, con discontinuidad o inversión del "tiempo diegético" (García Barrientos, 2012, p. 96) que responde al esquema: 1) final o catástrofe, 2) nudo o epítasis y 3) inicio o prótasis. Esta disposición ficcional aborda un hecho puntual de la historia argentina: el asesinato del referente militar y político Juan Lavalle en el año 1841, en la provincia de Jujuy. Este líder había participado en diversas contiendas emancipadoras de Sudamérica (junto con José de San Martín y Simón Bolívar, entre otros libertarios) hasta, finalmente, adherir a los idearios del unitarismo, cuya filiación fue la causa central de su persecución y muerte en mano de las huestes federales. Las misteriosas y polémicas versiones sobre su homicidio le permiten al dramaturgo componer un "bricolaje" mítico-imaginario (Wunenburger, 2008, p. 42), en el que se enlazan recursos de la mitología griega y cristiana con elementos populares propios de la cultura norteña.

Así, en el desarrollo de la acción la figura del prócer es tangencial o secundaria, ya que la fuerza actancial se encarna en el personaje Muchacha, la amante de Lavalle que presencia su muerte. En términos historiográficos, la joven representa a Damasita Boedo, la bella mujer - hija y hermana de congresistas asesinados por Lavalle- que es incorporada a las tropas como la cuartelera personal del líder durante su huida hacia el norte. En ella, el odio y el amor por el mencionado "héroe nacional" se confunden o mezclan sin límites precisos. No obstante, en esta recreación hay una evidente ruptura de las imágenes esencialistas que la asocian con la vulnerabilidad o la dependencia de un "macho" protector; en efecto, la obra relata cómo la Muchacha — junto con otros soldados unitarios - escapa con el cadáver de Lavalle hacia la frontera, con el fin de llegar a Potosí y evitar la captura y exhibición pública de los restos del general. En esta travesía por el desierto jujeño, el olor putrefacto del cuerpo tienta a los pumas y demora su traslado, entonces se decide descuartizar y deshuesar a Lavalle. El héroe - vehículo de connotaciones patriarcales y hegemónicas - ya no será un "héroe", sino un capital o bien de intercambio que le ayudará a la mujer a pervivir. Por lo tanto, el cuerpo de unos de los "padres de la patria", un protector amoroso de la "tierra", es desmembrado y engullido en una frontera geopolítica, pero también simbólico-identitaria.

En suma, la joven se viste con el traje militar de Lavalle y se fuga con los huesos y la cabeza del hombre envueltos en lonas, como así también con el corazón guardado en una jarra con aguardiente. En esta representación histórico-imaginaria la mujer es la "portadora" del cuerpo masculino, el que ha sido mutilado por efecto de su propio ejercicio de poder. Incluso, los restos óseos del prócer le permiten a la protagonista - en la estructuración ficcional de la pieza- cumplir con su objetivo central: cruzar la frontera y salvar su vida, pues ella utiliza las carnes del macho/captor como "anzuelo" o distracción para sus perseguidores, quienes ante la erotización política por los trozos del cadáver que encuentran en el camino, le otorgan a la Muchacha el tiempo suficiente para llegar a su destino, portando el corazón del líder, vale decir, el único fragmento del cuerpo que no ofrece de comer a los perros cazadores.

El "bricolaje" mítico-imaginario sobre lo femenino aludido anteriormente se completa con elementos de la cultura griega clásica y de la mística cristina, puntualmente, esta peripecia tiene aires de familia con el ciclo vital de Medea, la hechicera de Cólquida que - para huir junto con Jasón y los argonautas de las tropas de su padremata y despedaza a su hermano, con el propósito de arrojar al mar sus partes y distraer a su perseguidor. Asimismo, el texto - a través de la inversión 
temporal indicada - plantea una evolución que va desde lo onírico hasta lo fáctico. Para establecer esta lógica transicional en el relato, la acción inicia con la aparición de dos ángeles —entidades propias del sincretismo religioso cristiano y pagano-, quienes acosan e interrogan a la protagonista sobre las razones de su accionar y, de este modo, generan en la pieza una densidad hipertextual que garantiza su potencialidad semántica.

Por consiguiente, Cruzar la frontera expone una tensión productiva entre diversas configuraciones históricas y poéticas sobre la mujer, pero compiladas en una imagen férrea o incluso cuasimatriarcal, por medio de la cual se construye un posicionamiento estético contraesencialista sobre lo femenino, sin la reproducción pasiva o literal de los tópicos dictatoriales impuestos en los discursos públicos. Esta configuración puede resumirse en la presentación de la Muchacha, quien inicia la obra diciendo:

Anoche soñé que las criadas de mi casa llenaban la tina con jarras de sangre caliente para que me bañara, y sumergía mi cuerpo hasta el cuello y, cuando sentía que se enfriaba, pedía más. Entonces ellas iban a la plaza y decían que su niña necesitaba sangre caliente para el baño y allí había soldados que con un solo tajo en las venas volcaban sangre nueva en las jarras. (Accame, 2011, p. 61)

\section{Ideas finales}

La "nación feminizada", estudiada como una retórica corporal dominante en los discursos públicos (oficialistas y opositores) durante los años de violencia y terrorismo de Estado (1966-1983), obtiene en las distintas fases de la posdictadura argentina un proceso poético-teatral de reproducción, reanimación hermenéutica y autorregulación estética, evidenciado en las dramaturgias regionales del norte y el sur del país. Este proceso poético se manifiesta en la configuración contraesencialista de posicionamientos identitarios sobre la feminidad, al plasmar una lógica imaginaria dinámica, sin la deshistorización ni los reduccionismos propios de un nacionalismo sustancialista y paternalista aplicado al pensamiento de lo nacional. Por el contrario, las figuras y los tropos comentados en los estudios de caso muestran la "deriva" de este imaginario-poético en el campo teatral regional, esto último por su capacidad de reactivar en los textos determinados niveles sintácticos y semánticos, o también al sedimentar, autorregular y recrear distintos componentes genéricos, históricos o geoculturales.

Este proceso estético-identitario se objetiva en los dos ejes analizados: a) la reanimación hermenéutica del encierro y la locura del cuerpo/mujer; b) la impugnación del discurso tradicionalista y autoritario, mediante una resemantización de la mujer/ territorio. Pues, en estos sedimentos imaginarios, los tópicos esencialistas legados de la discursividad dictatorial confrontan en una semiosis alternativa - un "otro logos" (Drucaroff, 2016) - , con discursos y posicionamientos femeninos divergentes, los que resignifican las figuraciones de "la loca" o "la enferma ultrajada" y sus correlativos habitus de clase -expuestos, por ejemplo, en los casos de Clemencia, Hebras, y Siempre lloverá en algún lugar-; o también, se impugna la violación del cuerpo/territorio como una metáfora del control falo-logocéntrico, al contraponer un erotismo diferencial que resquebraja el ideologema de la Nación como tierra de hombres, configuraciones que se observan en los textos dramáticos Bálsamo, Cruzar la frontera, Camino de cornisa y Pasto verde.

Así, los discursos identitarios e imaginarios forjados hienden las concepciones biológicas e inmutables de los posicionamientos totalitarios, a través de feminidades plurales, dinámicas e históricas, proyectadas en un específico locus de enunciación regional. Vale decir, se consolida la puesta en crisis de la heteronormatividad asignada a los procesos de subjetividad posdictatoriales en los campos culturales y teatrales del norte y el sur. En suma, esta deriva imaginario-poética plantea su antiesencialismo en la configuración, legitimación e institucionalización de un feminismo diferencial, al ofrecer contradicciones, aporías o contrasentidos que cuestionan la concepción homogeneizadora de la "mujer" y de sus proyecciones políticas. 


\section{Referencias}

Accame, J. (2011). Teatro. Buenos Aires: Losada.

Aranzábal, M. (2015). Bálsamo. En M. Tossi (Comp.), Antología de teatro rionegrino en laposdictadura (pp. 157-172). Viedma: Universidad Nacional de Río Negro.

Banchs, M. A. (2007). Imaginarios, representaciones y memoria social. En A. Arruda y M. de Alba (Eds.), Espacios imaginarios y representaciones sociales. Aportes desde Latinoamérica (pp. 45-97). Barcelona: AnthroposUniversidad Autónoma Metropolitana de México. https://doi.org/10.2307/j.ctvckq982.11

Calcumil, L. y Fidel, V. (2015). Hebras. En M. Tossi (Comp.), Antología de teatro rionegrino en la posdictadura (pp. 203-210). Viedma: Universidad Nacional de Río Negro.

Castoriadis, C. (2013). La institución imaginaria de la sociedad. Buenos Aires: Tusquets.

Dargoltz, R. (2007). Clemencia. En Dramaturgos del noroeste argentino (pp. 120-141). Buenos Aires: Argentores.

Drucaroff, E. (2016). Otro logos. Signos, discursos, politica. Buenos Aires: Edhasa.

Dubatti, J. (2008). Cartografía teatral. Introducción al teatro comparado. Buenos Aires: Atuel.

Finzi, A. (2009). Tablón de estrellas. Buenos Aires: Colihue.

Foucault, M. (2010). El cuerpo utópico. Las heterotopias. Buenos Aires: Nueva visión.

García Barrientos, J. L. (2012). Cómo se comenta una obra de teatro. Ensayo de un método. México: Paso de Gato.

García Canclini, N. (1990). Culturas hibridas. Estrategias para salir y entrar de la modernidad. México: Grijalbo. https://doi.org/10.1080/13569329209361789

Grimson, A. (2012). Los limites de la cultura. Critica delasteorías de la identidad. Buenos Aires: Siglo Xxi. https:// doi.org/10.5433/1984-3356.2015v8n16p360

Jelin, E. (2002). Los trabajos de la memoria. Madrid: Siglo XXI.

Jelin, E. (2005). Los derechos humanos, entre el Estado y la sociedad. En Suriano, J. (Dir.), Nueva historia argentina. Dictadura y democracia (pp. 509-557). Buenos Aires: Sudamericana.

Kadir, D. (2002). Puntos cardinales, mundos ordinales, literatura comparada. En Martínez Fernández, José
Enrique (Ed.), Estudios de literatura comparada. Norte y Sur. La sátira. Transferencia y recepción de géneros y formas textuales (pp. 43-57). León, España: Universidad de León. https://doi.org/10.26754/ ojs_tropelias/tropelias.201712120

Lamas, M. (2000). Usos, dificultades y posibilidades de la categoría "género". En Lamas, Marta (Ed.), El género. La construcción cultural de la diferencia sexual (pp. 327-366). México DF: Universidad Nacional Autónoma de México. https://doi.org/10.20318/ femeris.2018.4083

Le Breton, D. (2002). Sociología del cuerpo. Buenos Aires: Nueva Visión.

Maccarini, M. (2014). De transformaciones y travestimientos. s. M. de Tucumán: Gexpress.

Mellado, L. (2010). La Patagonia y su literatura: unidad y diversidad multiforme. Comodoro Rivadavia, Argentina: Universidad Nacional de la Patagonia San Juan Bosco. https://doi.org/10.22185/24487147.2016.90.041

Mignolo, W. (2003). Los estudios culturales: geopolítica del conocimiento y exigencias/necesidades institucionales. Revista Iberoamericana, LXIX (203), 401-415. https://doi.org/10.5195/reviberoamer.2003.5667

Morin, E. (1994). Introducción alpensamiento complejo. Barcelona: Gedisa.

Muñoz, L. (2007). Pasto Verde. (Reflexión dramática en un acto). En Dramaturgos de la Patagonia Argentina (183-190). Buenos Aires: Argentores.

Palermo, Z. (1998). Historiografía, literatura y región. Revista Silabario, 1(1), 61-74.

Palermo, Z. (2005). Desde la otra orilla. Pensamiento crítico y politicas culturales en América Latina. Córdoba: Alción.

Proaño-Gómez, L. (2002). Poética, política y ruptura. Argentina 1966-1973. Teatro e identidad. Buenos Aires: Atuel.

Ricoeur, P. (2000). Del texto a la acción. Ensayos de hermenéutica II. Buenos Aires: Fondo de Cultura Económica.

Schnaith, N. (2005). La muerte sin escena. Buenos Aires: Leviatán.

Williams, R. (1994). Sociología de la cultura. Barcelona: Paidós.

Wunenburger, J. (2008). Antropología de lo imaginario. Buenos Aires: Ediciones del Sol.

How to reference this article: Tossi, M. (2019). Feminidades contraesencialistas en la dramaturgia argentina de la posdictadura: un estudio comparado de las regiones Noroeste y Patagonia. Íkala, Revista de Lenguaje y Cultura, 24(3), 589-604. Dor: 10.17533/udea.ikala.v24n03a01 